\title{
Midwives' engagement in smoking- and alcohol-prevention in prenatal care before and after the introduction of practice guidelines in Switzerland: comparison of survey findings from 2008 and 2018
}

Sakari Lemola ${ }^{1 *}$ (D, Anna Gkiouleka ${ }^{1}$, Natalie Urfer-Maurer ${ }^{2}$, Alexander Grob ${ }^{3}$, Katharina Tritten Schwarz ${ }^{3}$ and Yvonne Meyer-Leu ${ }^{4,5}$

\begin{abstract}
Background: Evidence suggests that cigarette smoking and alcohol consumption during pregnancy negatively impacts fetal health. Health agencies across countries have developed specific guidelines for health professionals in perinatal care to strengthen their role in smoking and alcohol use prevention. One such example is the "Guideline on Screening and Counselling for prevention of cigarette smoking and alcohol consumption before, during, and after pregnancy" introduced by the Swiss Midwives Association in 2011. The current study assesses the changes in midwives' engagement in smoking and alcohol use prevention before (2008) and after the introduction of the Guideline (2018). Further, the current study examines differences across regions (German vs. French speaking regions), graduation years (before and after the introduction of the Guideline) and different work settings (hospital vs. self-employed).
\end{abstract}

Methods: Survey data were collected in $2008(n=366)$ and in $2018(n=459)$. Differences in how midwives engaged in smoking and alcohol use prevention between 2008 and 2018 were assessed with chi-square tests, as were differences across German and French speaking regions, graduation years (before and after the introduction of the Guideline) and across different work settings (working in hospitals or as self-employed).

Results: An increase in midwives' awareness of the risks of consuming even small quantities of cigarettes and alcohol for the unborn child between 2008 and 2018 is evident. Explaining the risks to pregnant women who smoke or use alcohol remained the most frequently reported prevention strategy. However, engagement with more extensive smoking and alcohol use preventive strategies across the whole course of pregnancy, such as assisting women in the elaboration of a plan to stop smoking/alcohol use, remained limited.

Conclusions: Seven years after its introduction, the effectiveness of the Guideline in increasing midwives' engagement in smoking and alcohol use prevention appears limited despite midwives' increased awareness.

Keywords: Smoking prevention, Alcohol use prevention, Perinatal care, Midwives, Midwifery

\footnotetext{
*Correspondence: s.lemola@warwick.ac.uk

'Department of Psychology, University of Warwick, UK, University Road,

Coventry CV4 7AL, UK

Full list of author information is available at the end of the article
}

(c) The Author(s). 2020 Open Access This article is distributed under the terms of the Creative Commons Attribution 4.0 International License (http://creativecommons.org/licenses/by/4.0/), which permits unrestricted use, distribution, and reproduction in any medium, provided you give appropriate credit to the original author(s) and the source, provide a link to the Creative Commons license, and indicate if changes were made. The Creative Commons Public Domain Dedication waiver (http://creativecommons.org/publicdomain/zero/1.0/) applies to the data made available in this article, unless otherwise stated. 


\section{Background}

There is a large body of evidence to show that cigarette smoking and alcohol consumption during pregnancy negatively impacts fetal health $[1,2]$. Studies systematically report that smoking during pregnancy is associated with preterm delivery, low birth weight, and spontaneous abortion [3]. Similarly, higher levels of alcohol consumption in pregnancy is associated with negative birth outcomes and increased risk of neurodevelopmental disorders for the child $[1,4]$.

Since smoking and alcohol use related risks for prenatal and neonatal health are avoidable, national and international health institutions have increasingly emphasized the important role of healthcare professionals, especially midwives, in smoking and alcohol use prevention among pregnant women $[5,6]$. Midwives care for women during and/or after pregnancy, and are thus well-positioned for screening the smoking and alcohol use habits of women, and observing their exposure to passive smoke. Moreover, through building trusting and supportive relationships, midwives can effectively educate pregnant women about relevant risks for the child and can facilitate positive changes to women's behavioral patterns [7, 8]. Empirical evidence shows that in highincome countries, psychosocial interventions increase the rates of women who quit smoking during late pregnancy [9]. Further, counselling on smoking cessation has been shown to be particularly effective when it is used consistently throughout the course of pregnancy [10]. In accordance, health agencies across countries have developed specific guidelines for health professionals in order to strengthen their role in perinatal smoking and alcohol use prevention.

In 2005, a survey-based study commissioned by the Swiss Federal Office of Public Health (FOPH) revealed that around $10 \%$ of the pregnant women in Switzerland smoked daily, while $30 \%$ drank alcohol at least once per month, and $2.2 \%$ reported consuming at least four drinks on a single occasion at least once during pregnancy [11-13]. Another study examined pregnant women's alcohol use in 11 European countries and found that in Switzerland, alcohol consumption during pregnancy is higher (20.9\% of women) than in most other studied countries, including Norway (4.1\%), Sweden (7.2\%), and Poland (9.7\%) [14]. Furthermore, only around $66 \%$ of pregnant women reported having been screened for smoking during pregnancy and around 36\% reported having received screening for alcohol consumption during prenatal care [11-13], which suggests a lack of effective smoking and alcohol use prevention services in Switzerland.

In response to these figures and in accordance with the national strategy for the prevention of noncommunicable diseases in Switzerland [15], the Swiss
Midwives Association introduced the "Guideline on Screening and Counselling for prevention of cigarette smoking and alcohol consumption before, during, and after pregnancy" in 2011 (revised and updated version released in 2017). Its goal was to provide guidance for midwives' everyday practice regarding screening and consultation on cigarette and alcohol consumption among women before, during and after pregnancy [16, 17]. The practice Guideline includes a decision tree to facilitate decision-making and integrates smoking and alcohol prevention into the midwives' work routine suggesting the following action points: (1) Universal screening of pregnant women regarding smoking and alcohol use; (2) Informing all women about the smoking and alcohol use related risks for the child; (3) Recommending smoking cessation; (4) Recommending abstinence from alcohol during pregnancy; (5) Addressing the risks related to environmental smoke exposure; (6) Integrating counselling and/or intervention approaches including motivational interviewing [18] and the ' $5 \mathrm{~A}$ ' approach [19]; and (7) Referrals to specialist care for women with heavier smoking and/or alcohol use habits $[16,17]$. Similar guidelines have been implemented in other countries including the Netherlands [20, 21], Scotland [22], Australia [23], and Canada [24]. However, recent evaluation studies provide mixed findings regarding the extent with which they are implemented consistently [21-27].

The aim of the current study was to evaluate the extent to which midwives increased their engagement in smoking and alcohol use preventive activities after the Guideline was introduced. To achieve this aim, we assessed the change in midwives' screening and counselling practice in Switzerland, between 2008 (when the first survey with midwives was conducted, prior to the introduction of the Guideline) and 2018 (when a second survey was conducted including the same questions). Moreover, we examined changes in midwives' awareness of smoking and alcohol consumption related risks for the child as well as their perceived barriers to effective smoking and alcohol use screening and prevention. As a further aim of the study, we examined the extent to which engagement in smoking and alcohol use prevention in 2018 was related to (a) whether midwives graduated before or after the introduction of the Guideline in 2011, (b) regional differences (i.e. between the French and German speaking regions in Switzerland), and (c) differences across work settings (i.e. working in hospitals versus being self-employed).

\section{Methods}

Study settings \& respondents

In 2008, all midwives listed in the public phone book of Switzerland were contacted via regular mail and 
questionnaires were sent in their respective national languages (German, French, and Italian). In total, 1270 midwives were contacted, of whom 366 participated in the study $(28.8 \%$ of all the midwives registered in the phone book) [8]. In January 2018, the Swiss Association of Midwives provided us with the e-mail addresses of its members. In total, 3136 midwives were contacted, of whom 661 completed an online questionnaire $(21.1 \%$ of all the members of the Swiss Association of Midwives; it is possible that the response rate was lower in 2018 as the Members' list of the Swiss Midwife Association may have included individuals who were no longer practicing as midwives). All participants were assured that their email addresses were only to be used for recruitment reasons for the present study and that their data was anonymized. In the paper-based survey in 2008, participants gave written informed consent, while in the online survey in 2018, informed consent was provided by clicking a respective button.

In 2008, participants answered a questionnaire regarding their screening and counselling activities during prenatal care. In 2018, participants completed mostly the same questionnaire if they were mainly involved in prenatal, or in both prenatal and postnatal care. Participants who indicated that they were exclusively involved in postnatal care in 2018 completed a questionnaire with the same content but phrased according to their screening and counselling activities with women after childbirth $(N=202)$. The study received ethical approval by the Institutional Review Board of the Department of Psychology of the University of Basel as well as the Humanities and Social Sciences Research Ethics SubCommittee of the University of Warwick (158/17-18) and complies with the standards of the Declaration of Helsinki [28].

For comparisons between 2008 and 2018, we identified a subsample of midwives from both surveys according to the following criteria: i) being involved in prenatal care; ii) having their first consultation with the pregnant women before the 38th gestational week; and iii) had built a longer-term relationship (e.g. accompanying the women through pregnancy). Midwives who were solely involved in birth preparation services or postnatal care were excluded from these analyses. In 2008, 227 of the 366 participating midwives met the above inclusion criteria (62.0\%). In 2018, 459 of the 661 midwives answered the questions regarding prenatal care of which 300 (65.4\%) met the inclusion criteria. The sample characteristics are presented in Table 1 . The samples at both time points were comparable and included respondents who

Table 1 Sample Characteristics

\begin{tabular}{|c|c|c|c|c|}
\hline & $\begin{array}{l}\text { Year of study: } 2008 \\
(n=227)\end{array}$ & $\begin{array}{l}\text { Year of study: } 2018 \\
(n=300)\end{array}$ & $C i^{2} /$ t-test & $p$ \\
\hline Age M (SD) & $45.17(7.73)$ & $42.76(10.12)$ & 2.968 & 0.003 \\
\hline Female gender (\%) & $226(100)$ & $298(99.3)$ & 1.512 & 0.219 \\
\hline Years since graduation $M(S D)$ & $19.40(9.04)$ & $16.53(9.80)$ & 3.433 & 0.001 \\
\hline \multicolumn{5}{|l|}{ Employment setting $^{a}$} \\
\hline Hospital only (\%) & $60(26.4)$ & $89(29.8)$ & 0.655 & 0.418 \\
\hline Hospital \& additional setting (\%) & $81(35.8)$ & NA & & \\
\hline Self-employed only (\%) & $103(45.4)$ & $193(64.5)$ & & \\
\hline Self-employed \& additional setting (\%) & $145(64.2)$ & NA & & \\
\hline Doctor's practice only (\%) & $2(0.9)$ & $4(1.3)$ & & \\
\hline Other facility only (\%) & $18(7.9)$ & $13(4.3)$ & & \\
\hline Hospital \& Self-Employed (\%) & $14(6.1)$ & NA & & \\
\hline Hospital \& Doctor's practice (\%) & $1(0.4)$ & NA & & \\
\hline Self- employed \& Other facility (\%) & $23(10.1)$ & NA & & \\
\hline Self-employed \& Hospital \& Doctor's practice (\%) & $2(0.9)$ & NA & & \\
\hline Self-employed \& Hospital \& Other facility (\%) & $4(1.8)$ & NA & & \\
\hline Number of pregnancy checks M (SD) & $5.36(3.90)$ & $5.32(5.75)$ & 0.088 & 0.930 \\
\hline Gestational week of 1st pregnancy check M (SD) & $17.18(8.01)$ & $19.11(7.50)$ & -2.852 & 0.005 \\
\hline
\end{tabular}

$n$ of participants meeting pregnant women for the first time before the 38th gestational week

${ }^{a}$ In the 2008 assessment multiple responses were possible, i.e. midwives could indicate to be employed in more than one setting. In the 2018 assessment only one response option was possible (i.e. midwives indicated only their main employment setting). Additional Chi ${ }^{2}$ calculations were conducted comparing 'hospital \& additional setting' in 2008 [81 (35.8\%)] with 'hospital' in 2018 [89 (29.8)] that revealed a non-significant difference: Chi ${ }^{2}(1)=2.169, p=0.141 ;$ and comparing 'self-employed \& additional setting' in 2008 [145(64.2\%)] with 'self-employed' in 2018 [193 (64.5\%)] again with a non-significant difference Chi ${ }^{2}(1)=$ $0.009, p>0.927$ 
were similar in age, years after graduation, work settings (hospital vs. midwife practice), and geographical region (German vs. French speaking Switzerland).

\section{Measures}

The participants were asked questions that covered the seven components of the Guideline (i.e. their engagement in smoking and alcohol consumption screening and prevention) as well as additional questions about their perceptions regarding smoking and alcohol use related risks for the unborn child, and a self-evaluation of their effectiveness at smoking and alcohol use prevention. Specifically, they had to indicate whether they perceived smoking and alcohol use to be risky and to what extent (e.g. 'How do you assess the risks of 1-2 cigarettes consumption per day during pregnancy for the child?' and 'How do you assess the risks of drinking one glass of alcohol per day during pregnancy for the child?' answered with the options 'harmless'; 'slightly increased risk for the child'; 'significantly increased risk for the child'); whether they routinely asked all women about their smoking and alcohol use habits (e.g. 'Do you routinely ask pregnant women if they smoke cigarettes?' and 'Do you routinely ask pregnant women whether they consume alcohol?' answered with the options 'I ask every pregnant woman if she smokes/uses alcohol'; 'I ask when I suspect a pregnant woman of smoking/alcohol use'; 'I do not ask pregnant women if they smoke/use alcohol'); whether they implemented specific interventions when women reported smoking or alcohol use (e.g. 'How do you intervene when a pregnant woman claims to smokel consume alcohol during pregnancy?' with answers e.g. 'I explain in detail the risks of smoking/alcohol use for the child'); and whether they asked about women's exposure to passive smoking and their partner's smoking and alcohol use habits (e.g. 'Do you ask pregnant women if their partner smokes/uses alcohol?' answered with 'Yes, I ask if her partner smokes/uses alcohol' or 'No, I do not ask if her partner smokes/uses alcohol'). Finally, they had to answer questions about potential barriers that restrained them from addressing smoking and alcohol consumption in their everyday practice.

To improve comparability between the surveys from 2008 and 2018 the same answer format was used. Questions that were answered with four-point scales were recoded into binary variables (e.g. the item 'Perceived importance of partner's smoking' took 1 if the respondents had chosen 'rather high' or 'very high', and 0 if the respondents had chosen 'rather low' or 'very low') to communicate the results more effectively.

\section{Analysis}

In order to evaluate differences in attitudes and engagement in smoking and alcohol use prevention between
2008 and 2018, we conducted Chi-square tests for categorical variables (significance <.05). Moreover, in further analyses of the 2018 sample, we conducted Chisquare tests to evaluate differences between German and French speaking regions, differences between midwives who had graduated before or after the introduction of the Guideline using the year 2012 as the cut-off point, and between midwives working in different settings (i.e. working in hospitals vs. self-employed midwives).

Due to minor differences in the survey design between 2008 and 2018, direct comparison of the responses was not possible for three items. First, in the 2008 survey, midwives could choose multiple responses regarding their employment setting (i.e. midwives could indicate that they were employed in more than one setting), while in the 2018 survey, only one response option was possible (i.e. midwives indicated only their main employment setting). Hence, further Chi-square tests compared 'working in a hospital \& additional setting' in 2008 with 'working in a hospital' in 2018; and 'self-employed \& additional setting' in 2008 with 'self-employed' in 2018. Second, in the 2018 survey, multiple responses were possible for smoking-related advice items (i.e. midwives could indicate both 'advising to quit smoking' and 'advising to reduce smoking' as answers). Due to noncomparability of the response options, no statistical comparisons were conducted for that question. Finally, in the 2018 survey, multiple responses were possible regarding alcohol consumption advice (i.e. midwives could indicate that they advised both 'strict abstinence' and 'up to sipping from the glass'), but only one response option was provided in 2008. Hence, the Chi-square calculation compared respondents who reported 'strict abstinence' as sole advice given regarding alcohol consumption in 2008 and 2018.

\section{Results \\ Smoking related screening and Counselling}

Table 2 shows the differences in midwives' engagement in smoking prevention in prenatal care between 2008 and 2018 alongside the Chi-square test results. In 2018, midwives were more aware of the risks of smoking, particularly regarding smoking less than 10 cigarettes a day. For example, in 2018, 31.8\% of the participating midwives considered smoking 1-2 cigarettes per day as highly risky compared to only $10.3 \%$ in 2008 . Moreover in $2018,85.6 \%$ of midwives indicated that smoking 3-9 cigarettes per day was highly risky compared to $71.4 \%$ in 2008. The extent to which passive smoking was considered risky for the child remained large, whereby approximately $95 \%$ of the respondents in each study year reported that it involves a risk. 'Screening all pregnant women regarding their smoking habits during pregnancy' was consistently reported by the majority of 
Table 2 Smoking prevention in prenatal care in 2008 and 2018

\begin{tabular}{|c|c|c|c|c|c|c|}
\hline \multirow[t]{2}{*}{ Variables } & \multirow[t]{2}{*}{$\mathrm{N}$} & \multirow{2}{*}{$\begin{array}{l}\text { Year } 2008 \\
(N=227)^{a} \\
n(\%)\end{array}$} & $\begin{array}{l}\text { Year } 2018 \\
(N=300)^{a}\end{array}$ & \multirow[t]{2}{*}{$\mathrm{Chi}^{2}$} & \multirow[t]{2}{*}{ df } & \multirow[t]{2}{*}{$p$} \\
\hline & & & n (\%) & & & \\
\hline \multicolumn{7}{|l|}{ Risk perception: 1-2 cigarettes/day } \\
\hline harmless for the child & 519 & $48(21.5)$ & $20(6.8)$ & 47.991 & 2 & $<0.001$ \\
\hline slightly risky for the child & & 152(68.2) & 182(61.5) & & & \\
\hline highly risky for the child & & 23(10.3) & 94(31.8) & & & \\
\hline \multicolumn{7}{|l|}{ Risk perception: 3-9 cigarettes /day } \\
\hline harmless for the child & 518 & $0(0.0)$ & $0(0.0)$ & 15.695 & 1 & $<0.001$ \\
\hline slightly risky for the child & & 63(28.6) & $43(14.4)$ & & & \\
\hline highly risky for the child & & 157(71.4) & 255(85.6) & & & \\
\hline \multicolumn{7}{|l|}{ Risk perception: 10 or more cigarettes /day } \\
\hline harmless for the child & 520 & $0(0.0)$ & $0(0.0)$ & $\mathrm{N} / \mathrm{C}$ & & \\
\hline slightly risky for the child & & $0(0.0)$ & $0(0.0)$ & & & \\
\hline highly risky for the child & & $222(100)$ & 298(100) & & & \\
\hline \multicolumn{7}{|l|}{ Risk perception: sudden cessation } \\
\hline not risky for the child & 509 & $97(44.1)$ & 102(35.3) & 5.278 & 3 & 0.153 \\
\hline slightly risky for the child & 509 & 105(47.7) & $157(54.3)$ & & & \\
\hline highly risky for the child & 509 & $5(2.3)$ & $13(4.5)$ & & & \\
\hline I don't know & 509 & $13(5.9)$ & $17(5.9)$ & & & \\
\hline \multicolumn{7}{|l|}{ Risk perception: Passive smoking } \\
\hline Environmental smoke is a risk & 521 & 215(95.1) & 285(96.6) & 0.722 & 1 & 0.395 \\
\hline 'it is rather harmless' \& 'I don't know' & & $11(4.9)$ & $10(3.4)$ & & & \\
\hline \multicolumn{7}{|l|}{ Screening: Routinely asking all women whether they smoke } \\
\hline all women & 524 & 202(89.4) & 266(89.3) & 0.668 & 2 & 0.716 \\
\hline only those suspected for smoking & 524 & $22(9.7)$ & $27(9.1)$ & & & \\
\hline none & 524 & $2(0.9)$ & $5(1.7)$ & & & \\
\hline Screening: Asking about exposure to passive smoking & 515 & $123(54.4)$ & 134(46.4) & 3.294 & 1 & 0.070 \\
\hline Screening: Asking whether the partner smokes & 515 & $152(67.3)$ & 178(61.6) & 1.768 & 1 & 0.184 \\
\hline Perceived importance of partner's smoking (rather or very important) ${ }^{b}$ & 520 & 209(92.9) & 274(92.9) & 0.000 & 1 & 0.997 \\
\hline Routinely explaining to all women the risks of smoking for the child & 519 & $145(64.4)$ & $155(52.7)$ & 7.182 & 1 & 0.007 \\
\hline \multicolumn{7}{|l|}{ Stop smoking interventions with smokers } \\
\hline Explaining the risks for the child & 526 & 187(82.7) & 257(85.7) & 0.837 & 1 & 0.360 \\
\hline Repeatedly addressing smoking in consequent appointments & 526 & $126(55.8)$ & $150(50.0)$ & 1.71 & 1 & 0.191 \\
\hline Assisting in elaboration of a plan to stop smoking & 526 & 79(35.0) & 114(38.0) & 0.514 & 1 & 0.473 \\
\hline Providing information material to smokers & 526 & $36(15.9)$ & $69(23.0)$ & 4.033 & 1 & 0.045 \\
\hline Referral to an expert & 526 & $21(9.3)$ & $64(21.3)$ & 13.794 & 1 & $<0.001$ \\
\hline Referral to behavioral therapy & 526 & $9(4.0)$ & $16(5.3)$ & 0.52 & 1 & 0.471 \\
\hline Agreement to quit & 526 & 15(6.6) & $11(3.7)$ & 2.421 & 1 & 0.120 \\
\hline Nicotine replacement therapy & 526 & $12(5.3)$ & $22(7.3)$ & 0.873 & 1 & 0.350 \\
\hline no intervention & 526 & $18(8.0)$ & $6(2.0)$ & 10.531 & 1 & 0.001 \\
\hline \multicolumn{7}{|l|}{ Barriers: Reasons not to address smoking (rather or very true) ${ }^{c}$} \\
\hline Shortage of time & 445 & 20(9.6) & $34(14.3)$ & 2.325 & 1 & 0.127 \\
\hline $\begin{array}{l}\text { I already know many of the women and their smoking habits from } \\
\text { previous pregnancies }\end{array}$ & 475 & $70(33.7)$ & $87(32.8)$ & 0.036 & 1 & 0.850 \\
\hline Most women already know the risks & 486 & $98(46.7)$ & $116(42.0)$ & 1.041 & 1 & 0.308 \\
\hline
\end{tabular}


Table 2 Smoking prevention in prenatal care in 2008 and 2018 (Continued)

\begin{tabular}{|c|c|c|c|c|c|c|}
\hline \multirow[t]{2}{*}{ Variables } & \multirow[t]{2}{*}{$\mathrm{N}$} & \multirow{2}{*}{$\begin{array}{l}\text { Year } 2008 \\
(N=227)^{a} \\
n(\%)\end{array}$} & $\begin{array}{l}\text { Year } 2018 \\
(N=300)^{a}\end{array}$ & \multirow[t]{2}{*}{$\mathrm{Chi}^{2}$} & \multirow[t]{2}{*}{ df } & \multirow[t]{2}{*}{$p$} \\
\hline & & & n (\%) & & & \\
\hline Women with children are generally well informed about the risks & 485 & $89(42.6)$ & 107(38.8) & 0.719 & 1 & 0.396 \\
\hline It is not within my area of responsibility & 485 & $8(3.8)$ & $12(4.3)$ & 0.071 & 1 & 0.790 \\
\hline Uncertainty about clinical relevance of smoking & 475 & $26(12.3)$ & 36(13.6) & 0.178 & 1 & 0.673 \\
\hline Uncertainty about being able to intervene effectively & 483 & $68(32.4)$ & $89(32.6)$ & 0.003 & 1 & 0.959 \\
\hline Giving advice to smokers is not effective & 481 & $107(51.2)$ & 124(46.0) & 1.300 & 1 & 0.254 \\
\hline Pregnant women probably do not honestly report on smoking & 485 & $96(45.7)$ & $125(45.5)$ & 0.003 & 1 & 0.955 \\
\hline In vocational training I was not informed on the risks of smoking & 490 & $44(20.8)$ & $60(21.6)$ & 0.049 & 1 & 0.824 \\
\hline $\begin{array}{l}\text { Smoking in pregnancy is a matter of private life and should } \\
\text { not be interfered with }\end{array}$ & 490 & $16(7.6)$ & $9(3.2)$ & 4.711 & 1 & 0.030 \\
\hline \multicolumn{7}{|l|}{ Advice given regarding smoking ${ }^{\mathrm{d}}$ : } \\
\hline to quit & 523 & 109(48.9) & $89(29.7)$ & & & \\
\hline "to quit" \& "to reduce" & & NA & 144(48.6) & & & \\
\hline to reduce & 523 & $90(40.4)$ & $61(20.3)$ & & & \\
\hline not to change & 523 & $0(0.0)$ & $2(0.7)$ & & & \\
\hline
\end{tabular}

${ }^{a}$ The numbers of participants in analyses differ slightly due to missing values

${ }^{b}$ The answers ranged from very important to very irrelevant on a 4-point scale, we merged them into two categories: 'rather or very important' that took 1 and 'rather or very unimportant' that took 0

' The answers ranged from very true to very untrue on a 4-point scale, we merged them into two categories: 'rather or very true' that took 1 and 'rather or very untrue' that took 0

d In the 2018 assessment, multiple responses were possible, i.e. midwives could indicate both 'to quit' and 'to reduce' as answers. Due to non-comparability of the response options, no statistical comparisons were conducted

midwives, with 89.4 and $89.3 \%$ routinely engaging with this practice in 2008 and 2018 respectively. Similarly, the rates of screening for exposure to passive smoking and partner's smoking remained rather stable.

When asked about their actual engagement in smoking prevention, the rate of midwives who routinely explained the smoking related risks for the child to all women regardless of their smoking habits decreased from $64.4 \%$ in 2008 to $52.7 \%$ in 2018 . In contrast, the number of midwives who referred smoking pregnant women to an expert increased from $9.3 \%$ in 2008 to $21.3 \%$ in 2018. Further, midwives who reported no engagement in any intervention decreased from 8.0 to $2.0 \%$. As for more extensive interventions, no statistically significant changes were observed between the two study waves regarding addressing smoking repeatedly in subsequent consultations after the first one. Similar rates for 2008 and 2018 were also found for assisting women in the elaboration of a quit plan, provision of information material, referrals of smokers to behavioral therapy, attempts to set a smoking cessation agreement, and recommending nicotine replacement therapy.

Finally, the perceived barriers to addressing smoking during pregnancy also remained similar between 2008 and 2018, whereby the most often reported reasons were uncertainty about being able to intervene effectively, that pregnant women would not report smoking habits accurately, and that women were already well aware of the smoking related risks.

\section{Alcohol use related screening and counselling}

Regarding prevention of alcohol use, the $\mathrm{Chi}^{2}$ test results (Table 3) show that midwives' awareness of alcohol userelated risks for the child increased substantially in 2018 and particularly regarding smaller quantities of alcohol. The percentage of midwives who considered rarely sipping a glass of alcohol to be harmless decreased from $83.8 \%$ in 2008 to $60.6 \%$ in 2018 . Further, in 2018, 66.4\% of the midwives perceived drinking up to three glasses of alcohol per week as highly risky, and 94.7\% perceived drinking one glass of alcohol per day as highly risky. In 2008 , the respective rates were 24.3 and $66.5 \%$. However, screening for alcohol use during pregnancy remained equally frequent between 2008 and 2018 and so did asking distinct questions regarding frequency, average amount and type of alcohol consumption, as well as questions regarding partners' alcohol use habits. In contrast, the percentage of midwives asking pregnant women about binge drinking (defined as drinking 4 glasses of alcohol/occasion) increased from $8.0 \%$ in 2008 to $17.0 \%$ in 2018 .

Midwives' engagement with alcohol use prevention for pregnant women who reported alcohol use during pregnancy increased significantly from 2008 to 2018 as 
Table 3 Prevention of alcohol consumption in prenatal care in 2008 and 2018

\begin{tabular}{|c|c|c|c|c|c|c|}
\hline \multirow[t]{2}{*}{ Variables } & \multirow[t]{2}{*}{$\mathrm{N}$} & \multirow{2}{*}{$\begin{array}{l}\text { Year } 2008 \\
(N=227)^{\mathrm{a}} \\
\mathrm{n}(\%)\end{array}$} & $\begin{array}{l}\text { Year } 2018 \\
(N=300)^{a}\end{array}$ & \multirow[t]{2}{*}{ Chi-2 } & \multirow[t]{2}{*}{ df } & \multirow[t]{2}{*}{$p$} \\
\hline & & & n (\%) & & & \\
\hline \multicolumn{7}{|l|}{ Risk perception: rarely sipping on a glass of alcohol } \\
\hline harmless & 501 & 186(83.8) & 169(60.6) & 34.797 & 2 & $<0.001$ \\
\hline slightly risky & & $34(15.3)$ & $90(32.3)$ & & & \\
\hline highly risky & & $2(0.9)$ & $20(7.2)$ & & & \\
\hline \multicolumn{7}{|l|}{ Risk perception: 3 glasses/week } \\
\hline harmless & 501 & $50(22.9)$ & $5(1.8)$ & 108.889 & 2 & $<0.001$ \\
\hline slightly risky & & 115(52.8) & $90(31.8)$ & & & \\
\hline highly risky & & $53(24.3)$ & 188(66.4) & & & \\
\hline \multicolumn{7}{|l|}{ Risk perception: 1 glass/day } \\
\hline harmless & 504 & $4(1.8)$ & $0(0.0)$ & 68.274 & 2 & $<0.001$ \\
\hline slightly risky & & $70(31.7)$ & $15(5.3)$ & & & \\
\hline highly risky & & $147(66.5)$ & 268(94.7) & & & \\
\hline \multicolumn{7}{|l|}{$\begin{array}{l}\text { Risk perception: Sporadically alcohol use large amounts } \\
\text { ( } 4 \text { glasses/occasion) }\end{array}$} \\
\hline harmless & 503 & $1(0.5)$ & $0(0.0)$ & 2.358 & 2 & 0.308 \\
\hline slightly risky & & $8(3.6)$ & $6(2.1)$ & & & \\
\hline highly risky & & 211(95.9) & 277(97.9) & & & \\
\hline \multicolumn{7}{|l|}{ Screening: Routinely asking all women whether they consume alcohol } \\
\hline all & 508 & 188(83.2) & $231(81.9)$ & 0.144 & 2 & 0.931 \\
\hline only those suspected for alcohol use & & $30(13.3)$ & $40(14.2)$ & & & \\
\hline none & & $8(3.5)$ & $11(3.9)$ & & & \\
\hline \multicolumn{7}{|l|}{ Screening: Specific questions asked regarding alcohol } \\
\hline Frequency of alcohol use occasions & 497 & 205(90.7) & 254(93.7) & 1.591 & 1 & 0.207 \\
\hline Average amount of alcohol consumed & 497 & 172(76.1) & 203(74.9) & 0.096 & 1 & 0.757 \\
\hline Frequency of binge drinking (4 glasses on a single occasion) & 497 & 20(8.8) & $46(17.0)$ & 7.063 & 1 & 0.008 \\
\hline Type of alcoholic beverages consumed & 497 & $92(40.7)$ & $125(46.1)$ & 1.47 & 1 & 0.225 \\
\hline Screening: Asking whether the partner uses alcohol & 505 & $70(31.1)$ & $78(27.9)$ & 0.638 & 1 & 0.425 \\
\hline Perceived importance of partner's alcohol use (rather or very important) ${ }^{b}$ & 500 & $170(76.2)$ & $209(75.5)$ & 0.041 & 1 & 0.839 \\
\hline $\begin{array}{l}\text { Routinely explaining to all women the risks of alcohol consumption } \\
\text { for the child }\end{array}$ & 506 & 135(59.7) & $176(62.9)$ & 0.515 & 1 & 0.473 \\
\hline \multicolumn{7}{|l|}{ Stop alcohol drinking interventions when a woman uses alcohol: } \\
\hline Explaining the risks for the child & 508 & $181(80.1)$ & 253(89.7) & 9.344 & 1 & 0.002 \\
\hline Repeatedly addressing alcohol use in consequent appointments & 508 & $98(43.4)$ & $147(52.1)$ & 3.86 & 1 & 0.049 \\
\hline Assisting in elaboration of a plan to stop or reduce alcohol use & 508 & $31(13.7)$ & 64(22.7) & 6.652 & 1 & 0.010 \\
\hline Providing information material to alcohol users & 508 & 20(8.8) & 65(23.0) & 18.157 & 1 & $<0.001$ \\
\hline Referral to an expert & 508 & $100(44.2)$ & 135(47.9) & 0.663 & 1 & 0.416 \\
\hline no intervention & 508 & $13(5.8)$ & $15(5.3)$ & 0.045 & 1 & 0.832 \\
\hline \multicolumn{7}{|l|}{ Barriers: Reasons not to address alcohol use (rather or very true) $)^{c}$ : } \\
\hline Shortage of time & 429 & 19(9.4) & 26(11.5) & 0.524 & 1 & 0.469 \\
\hline $\begin{array}{l}\text { I already know many of the women and their habits from previous } \\
\text { pregnancies }\end{array}$ & 460 & $56(27.1)$ & $55(21.7)$ & 1.756 & 1 & 0.185 \\
\hline Most women already know the risks & 466 & $79(37.6)$ & $89(34.8)$ & 0.407 & 1 & 0.523 \\
\hline Women with children are generally well informed about the risks & 462 & $84(40.2)$ & $88(34.8)$ & 1.433 & 1 & 0.231 \\
\hline It is not within my area of responsibility & 466 & $10(4.8)$ & 10(3.9) & 0.224 & 1 & 0.636 \\
\hline
\end{tabular}


Table 3 Prevention of alcohol consumption in prenatal care in 2008 and 2018 (Continued)

\begin{tabular}{|c|c|c|c|c|c|c|}
\hline \multirow[t]{2}{*}{ Variables } & \multirow[t]{2}{*}{$\mathrm{N}$} & \multirow{2}{*}{$\begin{array}{l}\text { Year } 2008 \\
(N=227)^{a} \\
\mathrm{n}(\%)\end{array}$} & $\begin{array}{l}\text { Year 2018 } \\
(N=300)^{a}\end{array}$ & \multirow[t]{2}{*}{ Chi-2 } & \multirow[t]{2}{*}{$d f$} & \multirow[t]{2}{*}{$p$} \\
\hline & & & n (\%) & & & \\
\hline Uncertainty about clinical relevance of alcohol use & 459 & $39(18.8)$ & $31(12.4)$ & 3.604 & 1 & 0.058 \\
\hline Uncertainty about being able to intervene effectively & 464 & $59(28.1)$ & $70(27.6)$ & 0.016 & 1 & 0.898 \\
\hline Giving advice to alcohol users is not effective & 452 & $96(46.6)$ & $66(26.8)$ & 19.062 & 1 & $<0.001$ \\
\hline Pregnant women probably do not honestly report on alcohol use & 465 & $117(55.7)$ & $108(42.4)$ & 8.232 & 1 & 0.004 \\
\hline In vocational training I was not informed on the risks of alcohol use & 466 & $37(17.6)$ & 39(15.2) & 0.481 & 1 & 0.488 \\
\hline $\begin{array}{l}\text { Alcohol use in pregnancy is a matter of private life and should } \\
\text { not be interfered with }\end{array}$ & 464 & $11(5.2)$ & $6(2.4)$ & 2.694 & 1 & 0.101 \\
\hline \multicolumn{7}{|l|}{ Advice given regarding alcohol consumption ${ }^{\mathrm{d}}$ : } \\
\hline strict abstinence & 509 & $32(14.3)$ & 120(40.0) & 42.246 & 1 & $<0.001$ \\
\hline "strict abstinence" \& "never drink more than just sipping" & & NA & $45(15.7)$ & & & \\
\hline "strict abstinence" \& "reasonable consumption" & & NA & $3(1.0)$ & & & \\
\hline $\begin{array}{l}\text { "strict abstinence" \& "never more than just sipping" \& "reasonable } \\
\text { consumption" }\end{array}$ & & NA & $3(1.0)$ & & & \\
\hline "never drink more than just sipping" & 509 & 75(33.6) & $77(25.7)$ & & & \\
\hline "never drink more than just sipping" \& "reasonable consumption" & & NA & $14(4.9)$ & & & \\
\hline reasonable consumption ("a glass every now and then") & 509 & 109(48.9) & $21(7.0)$ & & & \\
\hline one glass/day & 509 & $2(0.9)$ & $0(0.0)$ & & & \\
\hline
\end{tabular}

${ }^{a}$ The numbers of participants in analyses differ slightly due to missing values

b The answers ranged from very important to very irrelevant on a 4-point scale, we merged them into two categories: 'rather or very important' that took 1 and 'rather or very unimportant' that took 0

' The answers ranged from very true to very untrue on a 4-point scale, we merged them into two categories: 'rather or very true' that took 1 and 'rather or very untrue' that took 0

${ }^{d}$ In the 2018 assessment, multiple responses were possible, i.e. midwives could indicate advising both 'strict abstinence' and 'up to sipping from the glass' (which may depend on circumstances. The $\mathrm{Chi}^{2}$ calculated is between respondents that have reported 'strict abstinence' as the only type of advice given regarding alcohol consumption in 2008 and 2018

identified by an increase in the rates of explaining the risk for the child, assisting in the elaboration of a quit or reduction plan, and providing information material. Further, regarding the perceived barriers to addressing alcohol use during pregnancy, midwives' beliefs that giving advice to pregnant women is not effective decreased over time (from $46.6 \%$ in 2008 to $26.8 \%$ in 2018) as did beliefs that pregnant women do not report alcohol use habits accurately (from 55.7 to $42.4 \%$ ). Finally, advising strict abstinence from alcohol use became more frequent in 2018 with $40.0 \%$ exclusively choosing this response option compared to $14.3 \%$ in $2008\left(\mathrm{Chi}^{2}(1)=42.246\right.$, $p<0.001)$.

\section{Differences between midwives from different regions, with different graduation years, and of different work settings \\ Smoking related screening and counselling}

Analyses of regional differences showed no significant differences between French and German speaking regions in terms of smoking screening, familiarity with the Guideline and most types of advice provided. However, in German speaking regions, midwives explained smoking-related risks for the child to smoking pregnant women more often than their counterparts in French speaking regions (89.3\% compared to $70.7 \%$ ), and they addressed smoking in consequent appointments more systematically $(56.2 \%$ compared to $24.1 \%$ in French speaking regions). However, the patterns were reversed regarding referrals of smoking women to an expert, referrals for behavioral or nicotine replacement therapy, assisting in the development of a cessation plan as well as the use of the Stages of Change Model of behavior change (Additional file 1: Table S1).

Looking at differences between midwives who graduated before the introduction of the Guideline (i.e. till 2011) and thereafter (Additional file 1: Table S3), we observed that overall, awareness of risks, familiarity with the Guideline and engagement in smoking prevention remained similar. However, midwives who graduated before 2012 routinely explained the smoking related risks for the child to all women and stressed the issue in consequent appointments more often than midwives who graduated in 2012 onwards. However, the latter appear to use the Stages of Change Model of behavior change more systematically (12.5\% compared to $1.8 \%)$. There are also some significant differences regarding the reasons reported for not addressing smoking. For midwives 
who graduated before 2012, the most often reported reason is the assumption that women already know the relevant risks, while for those who graduated in 2012 or later, the most often reported reason is their uncertainty surrounding their own effectiveness.

Finally, regarding differences across work settings (Additional file 1: Table S5), self-employed midwives compared to those working in hospitals seemed to feel more confident about the effectiveness of their own advice, they explained the smoking related risks for the child, they assisted smoking pregnant women in setting a cessation plan, and they screened the partner's smoking habits more often. Moreover, they were less affected by shortage of time regarding addressing smoking and they were less concerned about pregnant women's accuracy in answering smoking related questions.

\section{Alcohol use related screening and counselling}

Regarding differences across regions, we observed that midwives in French speaking regions routinely explained the alcohol use related risks for the child to all women more systematically than those working in German speaking regions (88\% compared to $57.4 \%$, Additional file 1: Table S2) and they assisted more often in setting an alcohol quitting plan. However, midwives in German speaking regions repeatedly addressed alcohol consumption in consequent appointments during pregnancy more than their counterparts in French speaking regions (57\% compared to $30.8 \%$ ). Finally, midwives in French speaking regions had greater knowledge regarding alcohol related fetal disorders and they advised strict abstinence from alcohol more systematically.

Regarding differences related to midwives across graduation years, there were no significant differences apart from the finding that midwives who graduated before 2012 explained the risks for the child to all women more often (Additional file 1: Table S4) and screened the average amount of alcohol consumed less often compared to midwives who graduated in 2012 or later (72.1\% compared to $87.8 \%)$. Overall, midwives who worked in hospitals and those who were self-employed reported similar patterns regarding alcohol- related screening and counselling (Additional file 1: Table S6).

\section{Discussion}

The present study aimed to evaluate the extent to which Swiss midwives increased their engagement in smoking and alcohol use prevention 7 years after the introduction of the Swiss Midwives Association's Guideline on screening and counselling for prevention of cigarette smoking and alcohol consumption. To achieve our aim, we compared midwives' engagement in smoking and alcohol prevention in prenatal care in 2008, before the Guideline of the Swiss Midwives Association was introduced, and in 2018. Further, we conducted analyses to explore the extent to which the observed differences among midwives in 2008 and 2018 were also subject to differences across regions, graduation years and work settings. Overall, in 2018, midwives appeared more aware of the risks of consuming even small quantities of cigarettes and alcohol for the unborn child. This was particularly pronounced in relation to alcohol use. However, engagement with smoking and alcohol consumption prevention remained rather stable at low levels particularly regarding more extensive intervention efforts, across the 10 years.

Overall, explaining the risks to pregnant women who smoke/ consume alcohol remained the most frequently reported prevention strategy $(>80 \%)$, while referring women who smoke to an expert, developing a quit or reduction plan with women who smoke/ consume alcohol, or providing women with information material remained at rather low levels despite an observed increase across the two study waves. This finding suggests that a large number of midwives were still rather reluctant to engage in more extensive smoking and alcohol use prevention interventions in 2018, which may be explained by the finding that despite the introduction of the Guideline, the midwives still considered their advice against smoking and alcohol use as relatively ineffective $[7,18,19]$.

To our knowledge, the contents of the Guideline have been integrated into Swiss midwives' formal training, through particular modules concerning smoking and alcohol consumption prevention among pregnant women and new mothers. However, the extent of training in the contents of the guidelines possibly differs across midwifery schools and regions of the country. Relatedly, we expected that the engagement in alcohol use and smoking prevention would differ according to whether midwives graduated before or after the introduction of the Guideline and between different work settings. Furthermore, we assumed that whether midwives work in a hospital or as self-employed would play a role, as contextual factors such as time pressure may differ. Still, our study showed that the emerging patterns appear to be largely consistent across regions, graduation periods and work settings, although there are few significant differences in specific screening strategies and in the reasons reported for not addressing smoking and alcohol use. Thus, the findings are only partially consistent with research in the Netherlands [25] suggesting that the implementation of smoking prevention counselling as well as the relative barriers acknowledged vary across professional groups. Also, they point to the importance of further exploring the reasons that prevent midwives in Switzerland from engaging more actively in smoking and alcohol use preventive strategies despite knowing the relevant risks. 
A domain where we did find differences between work settings is the opinion that pregnant women tend to misreport their smoking and alcohol use habits. This barrier to effective screening was more often mentioned by midwives working in hospitals, who also often reported that shortage of time was a barrier to addressing smoking. As a recent study [22] showed, a relationship of trust between midwives and pregnant women facilitates more authentic and accurate disclosure of substance use behaviors. Therefore, apart from integrating routine screening of smoking and alcohol use in prenatal care, it is also important that hospital work routines allow midwives sufficient time to develop a trusting relationship with pregnant women, which in turn may also improve effective substance use prevention.

Further, in terms of knowledge of the Guideline, our findings did not show any significant differences between midwives who graduated before and after the introduction of the Guideline in 2011. This indicates that the extent to which the Guideline has been integrated into midwives' training during the 7 years since its introduction has not been sufficient to meet the desired changes in midwives' practice. Emphasizing smoking and alcohol prevention in midwives' basic training should be combined with further educational activities that highlight the necessity of the Guideline and its implementation, as well as with raising midwives' awareness of the impact of their own advice [8].

Further, activities that aim to reduce midwives' tendency to believe that pregnant women underreport their smoking and alcohol use habits, and to increase midwives' motivation to actively engage with prevention [21, 29] might also be useful. Accordingly, our findings suggest that efforts should also focus on increasing midwives' knowledge and skills to use the decision-making aids outlined in the Guideline. This could involve training in motivational interviewing and engagement in discussions around sensitive topics [21] (e.g. personal life information or substance abuse), as well as the integration of simple applications in midwives' everyday practice, including digital applications or conventional tools like printed screening questionnaires, decision trees, and checklists. These would enable midwives to conduct the smoking and alcohol use screening more efficiently and to set quitting goals and behavior change interventions in a more structured way [29-31].

In sum, our findings indicate that the Guideline has not been particularly effective in increasing midwives' engagement in smoking and alcohol consumption prevention, since the changes between 2008 and 2018 were not large. Despite being more aware of the risks related to smoking and alcohol use in pregnancy, midwives still do not engage in smoking and alcohol use prevention in a consistent manner. This is particularly alarming given the increased prevalence of smoking and alcohol use during pregnancy in Switzerland [32, 33].

The present findings should be seen in the light of certain limitations. First, there were differences regarding the study design and data collection between the two study waves. In 2008, midwives with a record in the phone book completed a hardcopy questionnaire received via regular mail, while in 2018 the members of the Swiss Midwives Association were contacted by email and asked to complete the questionnaire online. Although the background information regarding the samples look similar between the two measurement time points (e.g. similar shares of participants were working in hospitals) it remains possible that there were differences between the two samples that have not been considered.

Second, in the current naturalistic study it was not possible to study a control group unexposed to the Guideline. Therefore, it is not possible to determine whether changes were actually due to the introduction of the Guideline by the Swiss Midwives Association. Third, due to anonymity of the responses it was not possible to match answers of midwives between 2008 and 2018, although it can be assumed that the samples were partly overlapping. Fourth, the use of an even-numbered Likert scale for certain items did not allow ambiguous answers to indicate an undecided response (i.e. potentially undecided respondents were forced to decide for one side in some items). Finally, it is possible that some of the answers were influenced by memory related biases or social desirability. Future research might benefit from integrating both the midwives' as well as the clients' reports of midwives' smoking and alcohol use prevention in order to account for potential response biases.

\section{Conclusions}

In conclusion, the findings indicate that 7 years after the introduction of the Guideline by the Swiss Midwives Association in 2011, midwives appear more aware of the risks of smoking and alcohol use during pregnancy. However, systematic engagement with preventive activities across the whole course of pregnancy such as assisting women in the elaboration of a plan to stop smoking/alcohol use remained relatively infrequent. This suggests that the effect of the Guideline in changing midwives' working practice has been limited and that future research should explore the reasons explaining the stable lack of engagement particularly in more extensive interventions. Further, our findings suggest that there should be greater emphasis on increasing midwives' familiarity with the Guideline, increasing midwives' self-efficacy, and improving the way in which clinical tools are available to them across different work settings, particularly in hospitals. To increase the effectiveness of counselling, midwives' vocational training may include practical training in intervention techniques 
such as motivational interviewing, and hospitals may adopt longer consulting sessions to enable midwives to develop a patient-centered approach and to build a relationship of trust with their clients and potentially their partners [34]. Further, conventional (e.g. printed leaflets) and digital means (e.g. screening texts or apps) may also contribute to the more structured and systematic engagement of the midwives in screening and preventive activities before, during and after the pregnancy period.

\section{Supplementary information}

Supplementary information accompanies this paper at https://doi.org/10 1186/s12884-019-2706-8.

Additional file 1: Table S1. Smoking prevention in prenatal care \& knowledge of the Guideline of the Swiss Midwives Association by region. Table S2. Prevention of alcohol consumption in prenatal care by region. Table S3. Smoking prevention in prenatal care \& knowledge of the Guideline of the Swiss Midwives Association by graduation year (before and after 2012). Table S4. Prevention of alcohol consumption in prenatal care by graduation year (before and after 2012). Table S5. Smoking prevention in prenatal care \& knowledge of the Guideline of the Swiss Midwives Association by work setting. Table S6. Prevention of alcohol consumption in prenatal care by work setting.

\section{Abbreviation}

FOPH: Federal Office of Public Health

\section{Acknowledgements}

We thank the Swiss Association of Midwives for the support in recruitment of the participants. Further, we thank the University of Warwick for funding the implementation of this study. Finally, we thank $\mathrm{H}$. Trower, PhD for kindly accepting to proof-read the manuscript.

\section{Authors' contributions}

SL: Conceptualization, Data Curation, Formal Analysis, Funding Acquisition, Project Administration, Data interpretation, Writing original draft, Review and Editing. AG (Anna Gkiouleka): Conceptualization, Data Curation, Formal Analysis, Data interpretation, Writing original draft, Review and Editing. NUM: Conceptualization, Data collection, Data interpretation, Review and Editing. AG (Alexander Grob): Data interpretation, Review and Editing. KTS: Conceptualization, Data interpretation, Review and Editing. YML: Conceptualization, Data interpretation, Review and Editing. All authors have read and approved the manuscript, and ensure that this is the case.

\section{Funding}

The study was funded by the Higher Education Innovation Fund (HEIF) (G.HFPS.0002). The funding source had no involvement in study design; in the collection, analysis and interpretation of data; in the writing of the report; and in the decision to submit the article for publication.

\section{Availability of data and materials}

The datasets used and/or analysed during the current study are available from the corresponding author on reasonable request.

\section{Ethics approval and consent to participate}

The authors confirm that the study received ethical approval by the Institutional Review Board of the Department of Psychology of the University of Basel as well as the Humanities and Social Sciences Research Ethics SubCommittee of the University of Warwick (158/17-18) date of approval: 25 September 2018 and complies with the standards of the Declaration of Helsinki (World Medical Association, 2011). Study participants provided informed consent before they were enrolled in the study. In the paper-based survey in 2008, participants gave written informed consent while, in the online survey in 2018, informed consent was provided by clicking a respective button.

\section{Consent for publication}

Not Applicable.

\section{Competing interests}

The authors declare that they have no competing interests.

\section{Author details}

${ }^{1}$ Department of Psychology, University of Warwick, UK, University Road, Coventry CV4 7AL, UK. ²Department of Psychology, University of Basel, Missionsstrasse 62, 4055 Basel, Switzerland. ${ }^{3}$ Department of Health Professions, Bern University of Applied Sciences, Murtenstrasse 10, CH-3008 Bern, Switzerland. ${ }^{4}$ School of Health Sciences (HESAV), Avenue de Beaumont 21, CH-1011 Lausanne, Switzerland. ${ }^{5}$ University of Applied Sciences and Arts, Western Switzerland (HES-SO), Av. de Provence 6, CH-1007 Lausanne, Switzerland.

Received: 25 February 2019 Accepted: 26 December 2019

Published online: 13 January 2020

\section{References}

1. Flak AL, Su S, Bertrand J, Denny CH, Kesmodel US, Cogswell ME. The association of mild, moderate, and binge prenatal alcohol exposure and child neuropsychological outcomes: a meta-analysis. Alcohol Clin Exp Res. 2014;38(1):214-26.

2. Mund M, Louwen F, Klingelhoefer D, Gerber A. Smoking and pregnancy-a review on the first major environmental risk factor of the unborn. Int Environ Res Public Health. 2013;10(12):6485-99.

3. Banderali G, Martelli A, Landi M, Moretti F, Betti F, Radaelli G, et al. Short and long term health effects of parental tobacco smoking during pregnancy and lactation: a descriptive review. J Transl Med. 2015;13(1):327.

4. Meyer-Leu Y, Lemola S. Association of moderate alcohol use and binge drinking during pregnancy with neonatal health. Alcohol Clin Exp Res. 2011; 35(9):1669.

5. World Health Organization. Roadmap for more effective implementation of the Framework Convention on Tobacco Control in the WHO European Region (2015-2025): Leaving tobacco use behind. 2015; http://www.euro. who.int. Accessed 1 Nov 2019.

6. World Health Organization. Guidelines for the identification and management of substance use and substance use disorders in pregnancy. 2014.

7. Herberts C, Sykes C. Midwives' perceptions of providing stop smoking advice and pregnant smokers' perceptions of stop-smoking services in the same deprived area of London. J Midwifery Womens Health. 2012; 57(1):67-73

8. Lemola S, Meyer-Leu Y, Samochowiec J, Grob A. Control beliefs are related to smoking prevention in prenatal care. J Eval Clin Pract. 2013;19(5):948.

9. Chamberlain C, O'Mara-Eves A, Oliver S, Caird JR, Perlen SM, Eades SJ, Thomas J. Psychosocial interventions for supporting women to stop smoking in pregnancy. Cochrane Database Syst Revs. 2013;10.

10. Wesselink SFO, Lingsma HF, Robben PB, Mackenbach JP. Provision and effect of quit-smoking counselling by primary care midwives. Midwifery. 2015:31(10):986-92.

11. Grob A, Lemola S. Substanzkonsum junger Eltern in der Schweiz: Schlussbericht einer Studie im Auftrag des Schweizerischen Bundesamtes für Gesundheit; 2005.

12. Lemola S, Grob A. Drinking and smoking in pregnancy: which questions do Swiss physicians ask? Swiss Med Wkly. 2007;137(3-4):66.

13. Grob A, Lemola S. Substanzkonsumscreening in der Schwangerschaftsvorsorge. Final report. Bern: Federal Office of Public Health; 2008.

14. Mårdby AC, Lupattelli A, Hensing G, Nordeng $\mathrm{H}$. Consumption of alcohol during pregnancy-A multinational European study. Women Birth. 2017; 30(4):e207-13.

15. Federal Office of Public Health (FOPH), Swiss Conference of the Cantonal Ministers of Public Health. National Strategy for the Prevention of NonCommunicable Diseases (NCD Strategy) 2017-2024. 2016.

16. Schweizerischer Hebammenverband. Guideline zu Screening und Beratung bei Zigaretten-und Alkoholkonsum vor, während und nach der Schwangerschaft. 2011; http://www.hebamme.ch/de/heb/lit/index.cfm.

17. Schweizerischer Hebammenverband. Guideline zu Screening und Beratung bei Zigaretten- und Alkoholkonsum vor, während und nach der 
Schwangerschaft 2017; http://www.hebamme.ch/X_data/lit_pdf/Guideline. pdf

18. Miller WR, Rollnick S. Motivational interviewing. Preparing people for change. New York: The Guilford Press; 2002.

19. World Health Organization. Toolkit for delivering the $5 A^{\prime}$ 's and $5 R^{\prime} s$ brief tobacco interventions in primary care. 2014;(Retrieved 04.01.2016).

20. de Vries H, Bakker M, Mullen PD, Van Breukelen G. The effects of smoking cessation counselling by midwives on Dutch pregnant women and their partners. Patient Educ Couns. 2006;63(1-2):177-87.

21. Hopman P, Springvloet L, de Jong SD, van Laar M. Quit-smoking counselling in Dutch midwifery practices: Barriers to the implementation of national guidelines. Midwifery. 2019;71:1-1.

22. NSW Ministry of Health. NSW Clinical Guidelines for the Management of Substance Use During Pregnancy, Birth and the Postnatal Period. Sydney: NSW Ministry of Health; 2014.

23. Carson G, Cox LV, Crane J, et al. Alcohol use and pregnancy consensus clinical guidelines. J Obstet Gynaecol Can. 2010;32:S1-32.

24. Carson G, et al. No. 245-Alcohol Use and Pregnancy Consensus Clinical Guidelines. JOGC. 2017;39(9):e220-54.

25. Meijer E, van der Kleij R, Segaar D, Chavannes N. Determinants of providing smoking cessation care in five groups of healthcare professionals: A crosssectional comparison. Patient Educ Couns. 2019:102(6):1140-9.

26. O' Brian P. Performance Measurement: A Proposal to Increase Use of SBIRT and Decrease Alcohol Consumption during Pregnancy. Matern Child Health J. 2014;18(1):1-9.

27. Longman JM, Adams CM, Johnston JJ, Passey ME. Improving implementation of the smoking cessation guidelines with pregnant women: How to support clinicians? Midwifery. 2018;1(58):137-44.

28. Bell R, Glinianaia SV, van der Waal Z, Close A, Moloney E, Jones S, AraújoSoares V, Hamilton S, Milne EM, Shucksmith J, Vale L. Evaluation of a complex healthcare intervention to increase smoking cessation in pregnant women: interrupted time series analysis with economic evaluation. Tob Control. 2018;27(1):90-8.

29. Segaar D, Bolman C, Willemsen MC, De Vries H. Identifying determinants of protocol adoption by midwives: a comprehensive approach. Health Educ Res. 2006;22(1):14-26.

30. Griffiths SE, Parsons J, Naughton F, Fulton EA, Tombor I, Brown KE. Are digital interventions for smoking cessation in pregnancy effective? A systematic review and meta-analysis. Health Psychol Rev. 2018;12(4):333-56.

31. Tombor I, Shahab L, Brown J, Crane D, Michie S, West R. Development of SmokeFree Baby: a smoking cessation smartphone app for pregnant smokers. Transl Behav Med. 2016;6(4):533-45.

32. Popova S, Lange S, Probst C, Gmel G, Rehm J. Estimation of national, regional, and global prevalence of alcohol use during pregnancy and fetal alcohol syndrome: a systematic review and meta-analysis. Lancet Glob Health. 2017:5(3):e290-9.

33. Bornhauser C, Quack Lötscher KC, Seifert B, Simões-Wüst AP. Diet, medication use and drug intake during pregnancy: data from the consecutive Swiss Health Surveys of 2007 and 2012. Swiss Med Wkly. 2017; 147(5152):1-13.

34. Gouilhers S, Meyer Y, Inglin S, Pfister Boulenaz S, Schnegg C, Hammer R. Pregnancy as a transition: First-time expectant couples' experience with alcohol consumption. Drug Alcohol Rev. 2019; https://doi.org/10.1111/dar. 12973

\section{Publisher's Note}

Springer Nature remains neutral with regard to jurisdictional claims in published maps and institutional affiliations.

Ready to submit your research? Choose BMC and benefit from:

- fast, convenient online submission

- thorough peer review by experienced researchers in your field

- rapid publication on acceptance

- support for research data, including large and complex data types

- gold Open Access which fosters wider collaboration and increased citations

- maximum visibility for your research: over $100 \mathrm{M}$ website views per year

At BMC, research is always in progress.

Learn more biomedcentral.com/submissions 